\title{
Women's Feelings regarding Vaginal Examination during Normal Childbirth
}

\author{
*Amira SF, ** Mona AE, *** Soad RA, ****Rehab MA \\ * Technical Nursing Institute, Faculty of Nursing, Benha University. ** Maternity and \\ gynecological nursing, Faculty of Nursing, Ain Shams University. *** Obstetrics and \\ Gynecological NursingFaculty of Nursing-Benha University.
}

\begin{abstract}
Aim: The study aimed to assess women's feelings regarding vaginal examination during childbirth. Design: Descriptive study design Setting: This study was conducted at labor unit of Obstetric and Gynecological Department at Benha university Hospital for all pregnant women in active phase of labor. Sampling: convenient sample included 200 pregnant women in active phase of labor were recruited in the current study. Tools: An interviewing questionnaire was used to collect data related to women's feelings regarding vaginal examination Results: The present study revealed that vaginal examination was conducted too frequently with range (5-12 times) by different providers and this increase women's feeling of pain. The proportion of women who received high frequency of vaginal examination during childbirth was significantly larger in primipara as compared to multipara. Conclusion: The study concluded that most of women had feeling of pain regarding vaginal examination during childbirth. Recommendation: Health care provider who conducted vaginal examination should be perform the ideal exam and only when necessary, carefully without causing pain, with minimal discomfort to women and with dignity.
\end{abstract}

Key words: Vaginal Examination, Feeling, Normal childbirth.

\section{Introduction}

Normal childbirth is an important life event and care practices that occur during labor that can have a lasting influence on the woman and the family. Vaginal examination (VE) is a physically routine procedure which can have psychological consequences causing disruption to the natural body rhythms as well as emotional and physical pain. The use of regular, routine vaginal examinations and assessment of the cervix have been described as the most important measure of labor progress (Abed El-Moniem \& Mohamady, 2016).

Many women dislike VE because they often feel painful, and can be performed with little accompanying information in a sometimes ritualistic or intimidating manner. Expressions of pain or discomfort during the examination could be an individual's response to fear and anxiety rather than actual physical trauma, and therefore the pain may be more psychological than physical. Pain during VE could also be related to the inadequate skill of the examiner. During labor, pain is part of the normal physiological process and may be influenced by psychological, spiritual and cultural factors. Hence the experience of undergoing $\mathrm{VE}$ can cause further pain during what is often already an extremely vulnerable and painful time for the woman (Foureur\& Dixon, 2010).

Currently, there is little published research that has examined the number of VE 
women receive in labor and the reasons given by health professionals for performing VE. Current UK guidelines recommend that VE are offered to women at regular intervals of not less than $4 \mathrm{~h}$ and only performed when justifiably necessary. However, many women may be receiving more VE than expected and justification may be interpreted differently by different midwives (Shepherd \&Cheyne, 2013).

\section{Significance of the study}

In Benha university hospital, the researcher observed that women are exposed to vaginal examination more frequently, unnecessary and most women suffer from physical and psychological pain during procedure. On other hand, there are study was conducted on Ain Shams maternity hospital by (Abed El-Moniem \& Mohamady, 2016); that was done to investigate the effect of vaginal examination frequency practice during normal childbirth on psychophysical condition of Egyptian women.

Although VE is a method for diagnosis of progress of labor during intrapartum care but can be uncomfortable for women and can increase the risk of chorioamnionitis. Thus, vaginal examinations should be performed thoughtfully and for necessary reasons (Borders et al., 2012).

This study is the first study conducted to assess women's feelings, regarding vaginal examination during normal childbirth at women health nursing in faculty of nursing, Benha University.

Aim of the Study:

The study aimed to: assess women's feelings regarding vaginal examination during childbirth. This aim will be achieved through:
- Identify feelings of women regarding vaginal examination.

- Assess women's response on actual performance of VE

\section{Research question:}

The current study is carried out to test the following:

- What are the women felled regarding vaginal examination during childbirth?

- How many providers did vaginal examination during childbirth?

- How many vaginal examinations are performed during normal childbirth?

\section{Subjects\& Methods}

\section{I-Technical design}

The technical design used for the study discussed the following categories; research design, setting of the study, sample of the study, subjects and methods of the study and tools of data collection.

\section{Research design:}

A descriptive design was used in this study.

\section{Setting:}

The study was conducted at labor unit of obstetrics and gynecology department, Benha University Hospital, for all pregnant women in active phase attending the unit for delivery.

\section{Sampling:}

- Sample type:

A convenient sample was used. 


\section{- Sample size:}

This study included two hundred (200) pregnant women attendant in active phase of labor through six months in the period between August 2016- January 2017.

\section{- Sample criteria:}

This study included pregnant women in active phase of labor ( $3 \mathrm{~cm}$ cervical dilation) of the first stage of normal childbirth and excluded to any chronic disease (cardiac disease, diabetes mellitus.....).

\section{- Sample technique:}

The sample of this study included all pregnant women attending labor unit for 6 months started from the beginning of August 2016 to the end of January 2017 and undergone normal childbirth.

\section{Tools of data collection:}

One type of data collection was used:

An interviewing questionnaire schedule was designed by the researcher after reviewing the related literature, it was included the following parts:

- Part I: Bio-socio-demographic characteristics such as age, residence, level of education and occupation.

- Part II: Obstetric history it comprised 4 questions includes gravidity, number of abortion, parity and mode of delivery.

- Part III: vaginal examination on admission composed of 5 questions includes cervical dilation, effacement, head descend, membrane condition (intensity) and uterine contractions.
- Part 4: Assess women's feeling regarding vaginal examination during childbirth, it is composed of 9 questions that include feelings during vaginal examination, type of pain, pain increases when provider skill is not enough........ by using modified feeling scale(Ethan Hein Blog,2010).

- little worried

- Worried

- Anxious

- painful

\section{Content validity:}

Tools of data collection were reviewed by a panel of (3) expertise and modification was considered according to their comment

\section{II-Operational design}

\section{- Preparatory phase:}

It included reviewing of the related literature and previous related studies by using books, articles, magazines and internet to identify women's feelings regarding vaginal examination during normal childbirth. Tool of data collection was developed under the supervision of the supervisors and checked its content validity by a group of expertise.

\section{Ethical considerations:}

- The aim of the study was explained to each woman before applying the tools to gain confidence and trust.

- Informed consent was obtained from participants. 
- No harm happened for women's

- The data was collected in confidential manner and a result was considered.

- Every woman had the right to withdraw at any time without giving reasons.

\section{- Pilot study:}

The pilot study was conducted on available women in active phase of first stage of labor during $10 \%$ of the duration of the study (18 days). It was done to evaluate the feasibility, clarity, objectivity, validity and reliability of the tools to find the possible obstacles and problems encountered during data collection.

\section{- Fieldwork:}

The field work of the current study was carried out from the beginning of august 2016 till the end of January 2017 covered six months. The study setting was visited 3times/week from $9 \mathrm{Am}$ to $1 \mathrm{Pm}$, until the predetermined data collection time was reached and the subjects with previous inclusion criteria were collected.

The researcher introduced herself and explained the aim of the study to the participants.

- An approval and oral consent was taken from each participants.

- The sheet was filled by the researcher through an interview with each woman.

- The researcher applied one tool to assess the general characteristics and feeling of women regarding VE during normal childbirth.

\section{Limitations of the study:}

-Lack of cooperation and carelessness of some women.

-Disturbance, noise and interruption while conducting the study.

-Inadequate privacy during individual interviews.

-Few studies examined women's feeling regarding VE during normal childbirth or explored providers' actual practices and none explored it in developing countries or the Middle East region so there are decrease and repetition in references in discussion.

\section{III- Administrative design}

Necessary official approval to conduct the study was obtained from the Dean of Faculty of Nursing to administrator of Benha university hospitals.

\section{Statistical design:}

After data collection, each sheet was scored; the collected data were coded, organized and categorized. Results were presented in tables and analyzed by using the Statistical Package for Social Sciences SPSS programs version (20). Numerical qualitative data were expressed as frequencies and percentages. As well, mean, Standard Deviation (SD), Chi-square and probability of errors ( $p$-value) test were used to examine the relation between qualitative variables.

\section{Significance of results was considered as the following:}

\&) There is no statistical significance difference when $p^{>} 0.05$.

\& There is statistical significance difference when $p \leq 0.05$. 
There is highly statistical significance difference when $p \leq 0.001$.

\section{Results}

Table (1) reveals that, $51.0 \%$ of the studied women's age ranged from 25 to less than 30 years with mean age of 27.09 \pm 3.8 . $75.0 \%$ of women were live in rural area,

$46.0 \%$ had a secondary level of education and $77.5 \%$ of women were not working.

Table (2) indicates that, $56.5 \%$ of the studied women had one to two numbers of pregnancies. $83.0 \%$ of women didn't happen to her abortion, $33.0 \%$ of them born once. $69.5 \%$ of women had normal vaginal delivery.
Figure (1) illustrates that, $57 \%$ of the studied women had both physical and psychological feeling of pain during performing VE.

Table (3) illustrates that, $37.0 \%$ of the studied women had from five to seven numbers of VE. $76.5 \%$ of women had from two to three numbers of providers who made VE and $77.0 \%$ of them male providers made VE to there.

Table (4) illustrates that the studied women's feeling (regarding type of provider) in relation to their personnel characteristics. It reveals that there was a significant relation between studied women's feeling (type of provider) and their age and education

Table (1): Frequency distribution of studied women regarding Bio socio- demographic data $(n=200)$.

\begin{tabular}{|c|c|c|}
\hline \multirow[b]{2}{*}{ Bio socio- demographic data } & \multicolumn{2}{|c|}{$\begin{array}{c}\text { Total subjects } \\
(\mathrm{n}=\mathbf{2 0 0})\end{array}$} \\
\hline & No. & $\%$ \\
\hline \multicolumn{3}{|l|}{ Age } \\
\hline $20-$ & 48 & 24.0 \\
\hline $25-$ & 102 & 51.0 \\
\hline $30-35$ & 50 & 25.0 \\
\hline $\mathrm{X}^{-} \pm \mathrm{SD}$ & $27.09 \pm 3.8$ & \\
\hline \multicolumn{3}{|l|}{ Residence } \\
\hline Rural & 150 & 75.0 \\
\hline Urban & 50 & 25.0 \\
\hline \multicolumn{3}{|l|}{ Educational qualification } \\
\hline Illiterate & 7 & 3.5 \\
\hline Primary & 62 & 31.0 \\
\hline Secondary & 92 & 46.0 \\
\hline University & 39 & 19.5 \\
\hline \multicolumn{3}{|l|}{ Occupational status } \\
\hline Not employ & 155 & 77.5 \\
\hline Employ & 45 & 22.5 \\
\hline
\end{tabular}


Table (2): Frequency distribution of studied women in relation to the obstetric history $(\mathbf{n}=\mathbf{2 0 0})$.

\begin{tabular}{|c|c|c|}
\hline \multirow[b]{2}{*}{ Obstetric history } & \multicolumn{2}{|c|}{$\begin{array}{l}\text { Total subjects } \\
(\mathbf{n}=\mathbf{2 0 0})\end{array}$} \\
\hline & No. & $\%$ \\
\hline \multicolumn{3}{|l|}{ Gravidity } \\
\hline $1-$ & 113 & 56.5 \\
\hline $3-$ & 66 & 33.0 \\
\hline $5-7$ & 21 & 10.5 \\
\hline \multicolumn{3}{|l|}{ No. of abortion } \\
\hline 0 & 166 & 83.0 \\
\hline 1 & 28 & 14.0 \\
\hline $2-$ & 6 & 3.0 \\
\hline \multicolumn{3}{|l|}{ Parity } \\
\hline 0 & 57 & 28.5 \\
\hline 1 & 66 & 33.0 \\
\hline 2 & 24 & 12.0 \\
\hline $3-$ & 53 & 26.5 \\
\hline \multicolumn{3}{|l|}{ Mode of delivery } \\
\hline Primigravida & 57 & 28.5 \\
\hline Normal vaginal delivery & 139 & 69.5 \\
\hline Instrumental vaginal delivery & 4 & 2.0 \\
\hline
\end{tabular}

Figure (1): Frequency distribution of the studied women's feeling regarding type of Pain $(\mathbf{n}=\mathbf{2 0 0})$.

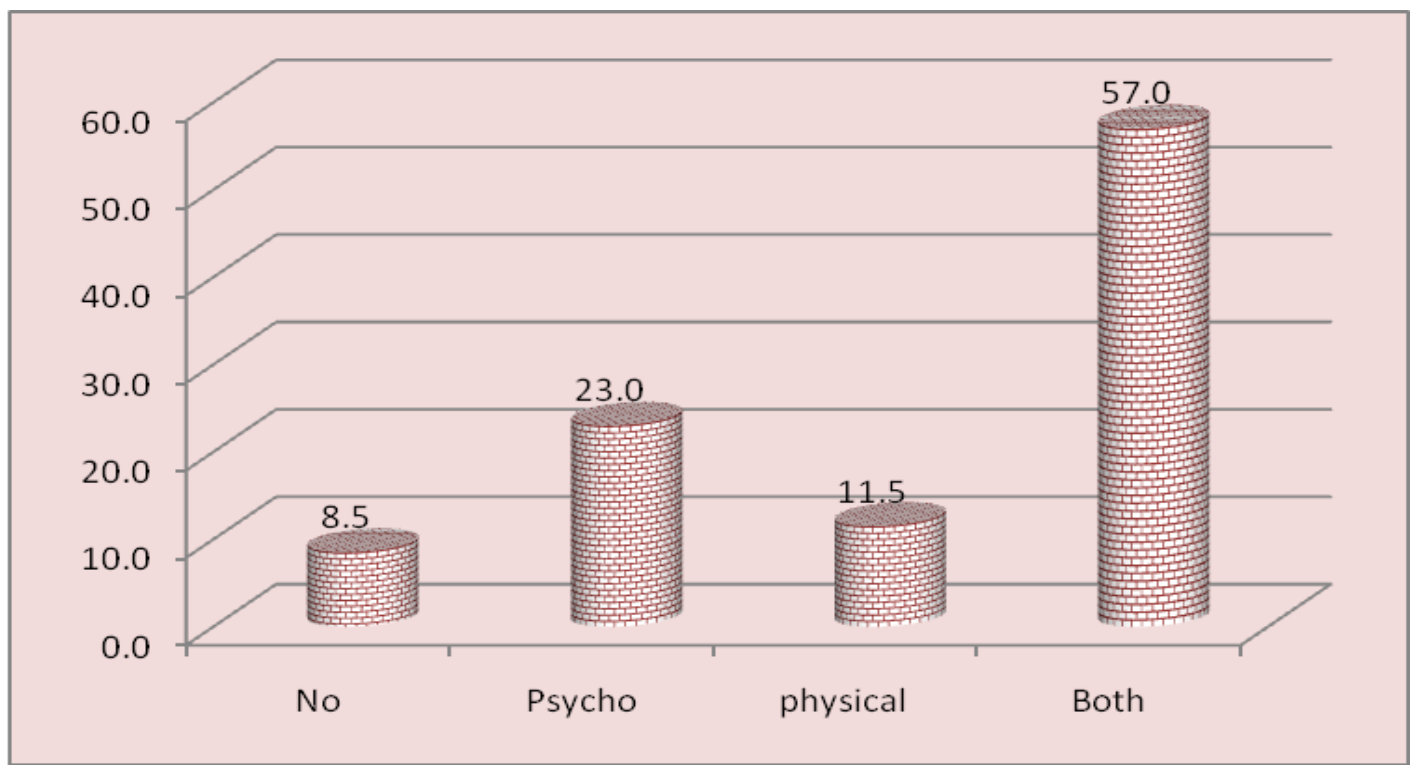


Table (3): Frequency \& distribution of items related to VE $(n=200)$.

\begin{tabular}{|l|c|c|}
\hline \multicolumn{1}{|c|}{ Items related to VE } & \multicolumn{2}{c|}{$\begin{array}{c}\text { Total subjects } \\
\text { (n=200) }\end{array}$} \\
\hline Numbers of VE & No. & \% \\
\hline $1-2$ & 22 & 11.0 \\
$3-4$ & 38 & 19.0 \\
$5-7$ & 74 & 37.0 \\
$8-12$ & 66 & 33.0 \\
\hline Numbers of health providers & \multicolumn{2}{|}{} \\
\hline One health provider & 17 & 7.5 \\
$2-3$ health provider & 153 & 15.0 \\
4-7 health provider & 30 & 77.0 \\
\hline Gender of provider & \multicolumn{2}{|c|}{} \\
\hline male & 154 & 23.0 \\
Female & 46 & \\
\hline
\end{tabular}

Table (4): Frequency distribution of study women between bio socio-demographic and feeling (pain regarding type of provider).

\begin{tabular}{|c|c|c|c|c|c|c|}
\hline & \multicolumn{2}{|c|}{ Female provider } & \multicolumn{2}{|c|}{ Male provider } & \multirow[t]{2}{*}{$\mathbf{x 2}$} & \multirow[t]{2}{*}{ p-value } \\
\hline & No & $\%$ & No & $\%$ & & \\
\hline \multicolumn{7}{|l|}{ Age (years) } \\
\hline $20-$ & 0 & 0.0 & 48 & 33.3 & \multirow{3}{*}{171.98} & \multirow{3}{*}{0.000} \\
\hline $25-$ & 6 & 10.7 & 96 & 66.7 & & \\
\hline $30-35$ & 50 & 89.3 & 0 & 0.0 & & \\
\hline \multicolumn{7}{|l|}{ Residence } \\
\hline Rural & 43 & 76.8 & 107 & 74.3 & \multirow[b]{2}{*}{0.132} & \multirow[t]{2}{*}{0.71} \\
\hline Urban & 13 & 23.2 & 37 & 25.7 & & \\
\hline \multicolumn{7}{|l|}{ Education } \\
\hline \multirow{5}{*}{$\begin{array}{l}\text { Illiterate } \\
\text { Primary } \\
\text { Secondary } \\
\text { University }\end{array}$} & 3 & 5.4 & 4 & 2.8 & & \multirow{5}{*}{0.03} \\
\hline & 25 & 446 & & 25 & \multirow{4}{*}{8.61} & \\
\hline & & & & & & \\
\hline & 21 & 37.5 & 71 & 49.3 & & \\
\hline & 7 & 12.5 & 32 & 22.2 & & \\
\hline \multicolumn{7}{|c|}{ Occupational status } \\
\hline \multirow{2}{*}{$\begin{array}{c}\text { Not employ } \\
\text { Employ }\end{array}$} & 42 & 75.0 & 113 & 78.5 & \multirow[b]{2}{*}{0.27} & \multirow[t]{2}{*}{0.59} \\
\hline & 14 & 25.0 & 31 & 21.5 & & \\
\hline
\end{tabular}

\section{Discussion}

Performing procedure of vaginal examination VE during normal labor can be considered both an intervention and an essential clinical assessment tool. Assessing cervical dilatation can help physician and midwives determine whether there is a normal presentation, position and rhythm to the labor. The World Health Organization (WHO) recommends that vaginal examination are offered to women at regular intervals of not less than 4 hours and only performed when justifiably necessary. In addition, it is a physically invasive procedure which can have psychological consequences causing disruption to the natural body rhythms as well as emotional and physical pain (Bonilla-Escobar et al., 2016). 
The current study is a descriptive study which aimed of to assess women's feelings regarding vaginal examination during childbirth. It was conducted at labor and delivery unit at obstetric and gynecological department in Benha university hospital.

The present study revealed that about half of studied women their age ranged from 25 to less than 30 years old with mean age $(27.09 \pm 3.8)$, this is may be due to most of women was multipara this finding came disagree with Abed El-Moniem \& Mohamady, (2016) who assessed effect of Vaginal Examination Frequency Practice during Normal Childbirth on Psychophysical Condition of Women; who found that the mean \pm SD of age was $(25.27 \pm 4.84)$ years.

Regarding level of education of the studied women, the present study showed that less than half of women had secondary school education followed by one third of them had primary education, this is may be due to most of women live in rural area which didn't care about educating girls, these finding is in the same line with JOSEPH (2015) who assess Women's Perception on Vaginal Examination in A Selected Hospital, Mangalore. Who revealed that about half of women had a secondary education and about one third had primary education.

The finding of the study revealed that majority of women lived in rural area, this finding came in the same line with Hassan et al. (2012)who assess the paradox of vaginal examination practice during normal childbirth: Palestinian women's feelings, opinions, knowledge and experiences and found that majority of women live in rural area.

Regarding feeling of women this study revealed that majority of women was feeling of pain during vaginal examination, this is may be due to procedure of VE is painful already or may be due to psycho causes and negative experience of women regarding VE, this finding in the same line with Abed El-
Moniem\& Mohamady, (2016) who found also that most of women feeling of pain during performing VE.

The result of the study showed that majority of women have physical and psychological pain and this disagree with Dixon \&Foureur, (2010) who state that the vaginal examination during labor: Is it of benefit or harm? And express on pain or discomfort during the examination could be an individual's response to fear and anxiety rather than actual physical trauma, and therefore the pain may be more psychological than physical.

The result of the present study is revealed that majority of women reported receiving a high' number of vaginal examination VE ranged (5-12) during their childbirth and increased as the labor time increased by many different providers this is may be due to midwives want to follow progress of labor and increase crying of women. This finding is higher than the recommendation of World Health Organization which recommended that vaginal examination should be conducted at 4-hour intervals and by the same provider if possible (World Health Organization (WHO),2012).

\section{Conclusion}

In the light of the study finding, some important facts could be concluded: The study concluded that most of women had feeling of pain regarding vaginal examination during childbirth. Majority of women reported receiving a high number of vaginal examination by many different providers. Primipara woman examined more frequently unnecessarily than multipara.

\section{Recommendations}

In the light of the present study findings, the following recommendations are suggested: 
Guidelines booklets about benefits

and harms of VE should be performed and available at labor

- unit of obstetric and gynecological department in Benha University.

- Medical and midwifery students should be taught not only to acquire the skill to conduct vaginal examination, but also should learn how to respect women during this crucial time.

- Health care provider who conducted VE should be perform the ideal exam and only when necessary, carefully without causing pain, with minimal discomfort to women and with dignity.

- Adhering to best evidence includes that vaginal examination during labor is conducted only when necessary and by the same provider as possible.

- Further studied need to be performed about increase women's awareness regarding benefits \& harms of vaginal examination and how to cooperate with health care provider.

\section{References}

Abed El-Moniem, E, \&Mohamady, S. (2016): Effect of Vaginal Examination Frequency Practice during Normal Childbirth on Psychophysical Condition of Women. IOSR Journal of Nursing and Health Science; available at: www.iosrjournals.org/iosrjnhs/papers/vol5-issue6/Version6/F0506063644.pdf

Bonilla-Escobar, F., Ortega-Lenis, D., RojasMirquez, J.\&Ortega-Loubon, C. (2016):
Panamanian Women's Experience of Vaginal Examination in Labor: A Questionnaire Validation, ELSEVIER, Midwifery 36:8-13 Available at: journal homepage: www.elsevier.com/midw

Borders, N., Lawton, R. \&Martin, S. (2012): A Clinical Audit of the Number of Vaginal Examinations in Labor: A NOVEL idea. Midwifery Women's Health. 57:139-44. Available at:https://www.ncbi.nlm.nih.gov/pubmed.

Dixon, L., \&Foureur, M. (2010): The Vaginal Examination during Labor: Is It of Benefit or Harm? New Zealand College of Midwives. 42:21-26. Available at:

https://opus.lib.uts.edu.au/bitstream/1045

Hassan, S., Sundby, J., Husseini, A., \&Bjertness, E., (2013): The Paradox of Vaginal Examination practice during Normal Childbirth: Palestinian Women's Feelings, Opinions, Knowledge and Experiences. Report Health. 9:16. Available at: URL:http://www.reproductive- health journal. Com/content/9/1/16 abstrac.

Joseph,R.(2015): A descriptive study to assess women's perception on vaginal examination in A selected. Hospital, Mangalore.PARIPEX- Indian journal of research, 4(6), 2250-1991.

Muliira, R.S., Seshan, V., \&Ramasubramaniam, S. (2013): Improving Vaginal Examinations Performed by Midwives Sultan, QaboosUniv Med J. August; 13(3): 442449. Available at: URL:http://www.ncbi.nlm.nih.gov/pmc/a rticles/. 